\title{
III. A capillary multiplier
}

\section{A.M. Worthington M.A.}

To cite this article: A.M. Worthington M.A. (1885) III. A capillary multiplier, Philosophical Magazine Series 5, 19:116, 43-46, DOI: 10.1080/14786448508627637

To link to this article: http://dx.doi.org/10.1080/14786448508627637

$$
\text { 册 Published online: } 29 \text { Apr } 2009 .
$$

Submit your article to this journal

LII Article views: 2

Q View related articles ¿ 
III. A Capillary Multiplier.

By A. M. Worthington, M.A.*

[Plate I. figs. $1 \& 2$.

THIS little instrument (Plate I. fig. 1) consists simply of a 1 rectangular strip of platinum foil of known length rolled into a cylindrical coil, whose successive convolutions are kept separate at a distance of about $2 \mathrm{~mm}$. by means of a strip of glass beads in the upper portion of the coil. The lower edges of all the convolutions are in the same plane; and the instrument when in use hangs from one end of a balancebeam with this plane horizontal.

The liquid whose surface-tension is to be determined is placed below the coil in a vessel which can be raised till the free surface touches the base of the coil. The pull now exerted on the coil is measured by weights placed in the other pan ; and these weights afford, when certain precautions shortly to be mentioned are taken, an accurate measure of the surface-tension of the liquid.

The method is really that used twenty years ago by Wilhelmy $\uparrow$, and more recently by $M$. Dupré $\ddagger$, who, however, employed only a single cylindrical sheet of platinum instead of a coil, and an hydrometer instead of a balance for measuring the pull.

The only novelty lies in the substitution of the coil for the single sheet,. by which the sensitiveness of the method is increased many-fold.

The principles involved may be briefly explained as follows : When any liquid is placed in a vessel whose sides it wets, $i . e$. against which the edge-angle of the liquid is $0^{\circ}$, the liquid is raised round the edge above the level of the free surface, and the weight of liquid so raised is equal to the surfacetension of the liquid multiplied by the periphery across which the snrface-tension acts. When the periphery $(p)$ is known and the weight $(u)$ of liquid raised is known, then the tension per unit of length is known to be $\frac{w}{p}$.

When a capillary tube is used for measuring the surfacetension, the periphery across which the force acts is the internal perimeter of the tube, and this is too small to be

* Communicated by the Physical Society: read November 22, 1884 (communicated by J. H. Poynting).

$\dagger$ Poggendortf's Annalen, 1863, No. 6, p. 177.

† See Théorie mécanique de la Chaleur, par M. A. Dupré (Paris, 1869), p. 245 et seq. 


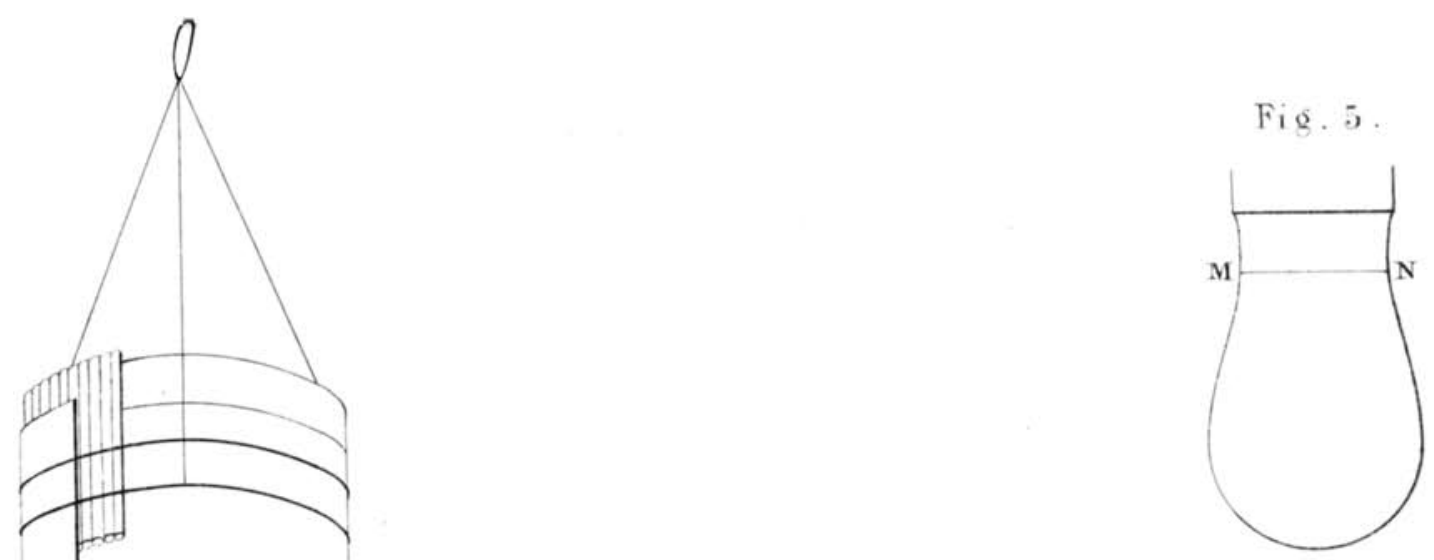

Fig. 1.
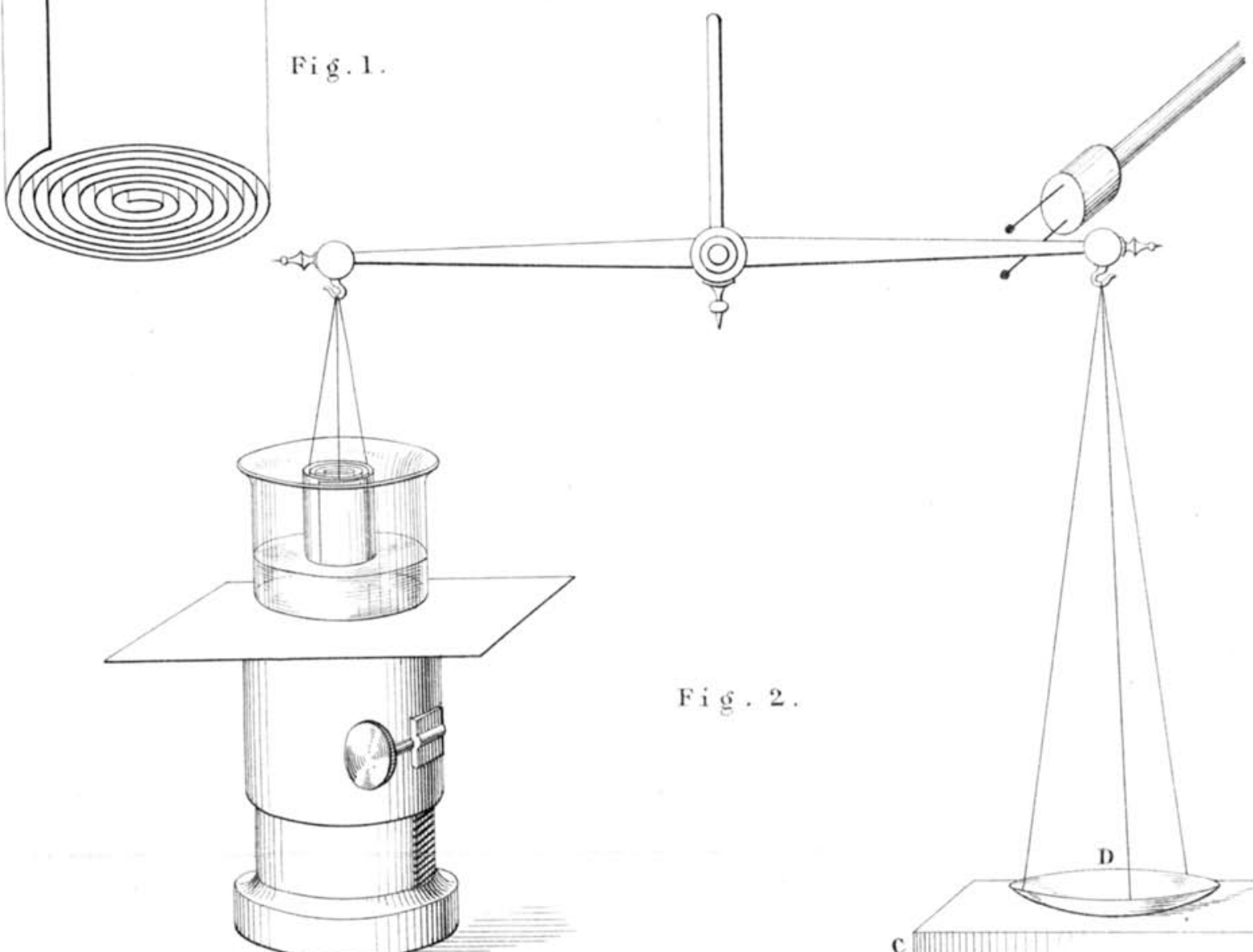

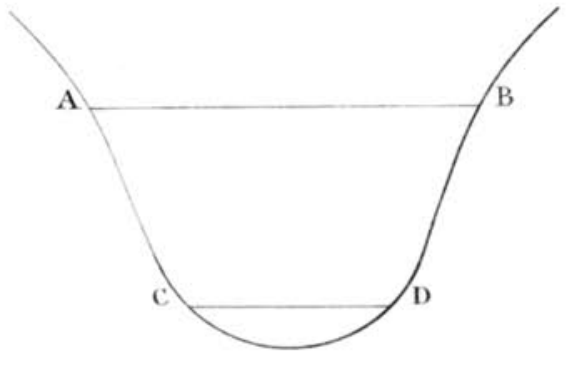

Fig. 3 . 
capable of very exact measurement ; while the weight of liquid raised is that of a column whose height can indeed be accurately measured, but whose sectional area is again too small to be very correctly determined.

If a very wide tube be used, the perimeter can be measured with much greater accuracy ; but the weight of liquid raised cannot now be determined in the same way as before, since the volume included between the surface of the meniscus and a horizontal plane touching its lowest point is now an important part of the whole volume raised. But the weight of the liquid raised along both the inside and outside perimeters of the tube is equal to the reactionary pull downwards of the liquid on the tube and may be determined by measuring this latter.

M. Dupré's wide cylinder of platinum foil was simply a tube whose inner and outer perimeters were sensibly equal and accurately known, and the pull across this perimeter could be determined in the way described.

The great advantage of the cuil over the single sheet is that the periphery across which the tension acts may be made very great, while the diameter of the coil, and consequently the quantity of liquid required and the area of its exposed surface, remains small.

Thus one of my coils is made of a strip 50 centim. long and presents a perimeter of 1 metre, while its diameter is only 3 centim., and the pull of water on this is about 8 grams.

The beads of which the strip is composed for separating the convolutions are made of hard glass, and strung on fine platinum wire, so that the instrument may be very readily cleaned by heating to a bright heat in the Bunsen flame. The beads should not reach within 2 or 3 centim. of the lower edge of the coil, in order that the liquid which rises between the convolutions may not reach so high as to wet the glass. If the consecutive coils are 2 miltim. apart, then water (which is raised higher than any other known liquid) will attain a height of about 8 centim. But since the coil is liable to be dragged down into the liquid, it is well to leave an ample margin.

If the coil dips below the plane surface of the liquid, there is a correction necessary on account of the buoyancy of the liquid. If, on the other hand, the base of the coil is raised above the free surface, there is a traction to correct for, due to the adhesion of the liquid to the horizontal section of the spiral edge. By adjusting the level of the liquid-surface after it has wetted the coil to the level of the base of the coil, when the balance-beam is horizontal, the necessity for these 
corrections is avoided. The thickest foil that $I$ use is $\cdot 0025$ centim. thick, and the correction due to an error of adjustment of the surface, amounting to 1 millim., would, in a measure of the surface-tension of alcohol, amount to $\frac{1}{2} \frac{1}{6}$ of the whole ; and it is easy to make the adjustment within much narrower limits than 1 millim.

\section{Method of Use.}

In order to prevent the coil from being dragged below the surface, or, on the other hand, separated from it, I find it convenient to fix two stops $A$ and $B$ (see fig. 2), just above and below the beam of the small unmounted balance that I employ : two stout pins stuck in a cork that is held in its place by a rod (as in the figure) serve the purpose very well.

After cleaning the coil in the Bunsen flame, adjusting its base so as to be horizontal by means of the three suspending cords, which are made of silk and are provided with beils through which the silk forms nooses like a tent-rope, and accurately counterpoising, a block $\mathrm{C}$ is placed below the right-hand pan at such a height that the pan rests on it when the beam is horizontal. Then the liquid to be tested is placed in a thin beaker, which stands on a small table, whose height can be easily adjusted by a ratchet-screw (the end of an optical lantern with a card on the top does very well). This is raised till the platinum is wetted, when it is at once drawn as far below the surface ( 4 or 5 millim.) as the position of the stop $A$ will permit. The pan $D$ is now pressed down by hand on the block $\mathrm{C}$ and held there, while the level of the liquid surface is adjusted to the base of the coil. Then $D$ is released, $\mathrm{C}$ removed, and weights added to restore equilibrium.

It will be observed that the coil is, by the process of putting on the weights, gradually drawn out of the liquid, so that the topmost element of the elevated liquid will everywhere be in contact with a portion of the coil that has been thoroughly wetted, which will with most liquids reduce the contact-angle to zero.

A few points may be usefully mentioned about the construction of the coil. To make the strip of glass beads I use combustion-tubing drawn out to a diameter of about 2 millim. and cut first into lengths of about 20 centim. Ont of a number of such pieces, a careful selection is made of those of most uniform thickness; these are then accurately cut to a length of about 2 centim., and of the beads thus made the strip is put together by passing through each in turn in opposite directions the two ends of a fine platinum wire (size no. 36). The smoothness of the glass strip allows the platinum coil to 
slide within it, so that by gentle pressure against a hard plane surface the edges of the convolutions can at any time be very accurately adjusted to the same plane. Other forms might doubtless be given to the multiplier, but the cylindrical coil is the most compact and requires for its use the smallest amount of liquid. The labour of double-threading the long strip of beads is considerable, and I have tried to avoid it by substituting a strip of asbestos cardboard, which would allow the coil to be cleansed by the action of the flame as before. But though in other respects satisfactory, the asbestos very rapidly gains in weight through the absorption of the vapour of many liquids, and cannot therefore be used unless wrapped in very thin platinum foil; but when so wrapped it is troublesome to coil, and does not allow the same ready adjustment of the edges of the coil to one plane.

Clifton College, Bristol, October 16, 1884.

IV. Note on a Point in the Theory of Pendent Drops. By A. M. Worthington, M.A. *

[Plate I. figs. 3-5.]

TN a paper on Pendent Drops (Proc. Roy. Soc. no. 214, 1881) I explained how, from a tracing of the outline of a drop pendent from a circular base, the value of the surfacetension of the liquid could be deduced with an accuracy that compared favourably with that of any other method.

The most difficult part of the process is the measurement at various levels of the inclination of the tangent of. the curve to the axis ; and I find that this difficulty does not disappear, as $I$ hoped it might, when a photograph of the magnified image of the drop is substituted for a tracing made by hand.

It is essential to the success of the method to measure this inclination at levels where the horizontal sectional area of the drop is widely different. Thus in a drop shaped as in fig. 3 Plate I. it would be desirable to measure the inclination, say, at the level $A B$ and again at the level $C D$. Now at $A B$, where the inclination changes very slowly, its value may be very accurately determined; but at CD the change of inclination is rapid and its determination difficult.

It has lately occurred to me that the necessity of finding the value of the inclination at more than one level may be

* Communicated by the Physical Society: read November 22, 1884 (communicated by J. H. Poynting). 